\title{
Unmanned Aerial Mass Spectrometer Systems for In-Situ Volcanic Plume Analysis
}

\author{
Jorge Andres Diaz, ${ }^{1}$ David Pieri, ${ }^{2}$ Kenneth Wright, ${ }^{3}$ Paul Sorensen, ${ }^{4}$ Robert Kline-Shoder, ${ }^{4}$ \\ C Richard Arkin, ${ }^{5}$ Matthew Fladeland, ${ }^{6}$ Geoff Bland, ${ }^{7}$ Maria Fabrizia Buongiorno, ${ }^{8}$ \\ Carlos Ramirez, ${ }^{9}$ Ernesto Corrales, ${ }^{1}$ Alfredo Alan, ${ }^{1}$ Oscar Alegria, ${ }^{1}$ David Diaz, ${ }^{1}$ \\ Justin Linick ${ }^{2}$ \\ ${ }^{1}$ Physics School, GasLab, CICANUM, Universidad de Costa Rica, San José, Costa Rica \\ ${ }^{2}$ Jet Propulsion Laboratory, California Institute of Technology, Pasadena, CA, USA \\ ${ }^{3}$ INFICON Inc., East Syracuse, NY, USA \\ ${ }^{4}$ CREARE LLC., Hanover, NH, USA \\ ${ }^{5}$ Engineering Services Contract, Kennedy Space Center, Cape Canaveral, FL, USA \\ ${ }^{6}$ National Aeronautics and Space Administration (NASA), Ames Research Center, Mountain View, CA, USA \\ ${ }^{7}$ National Aeronautics and Space Administration (NASA), Goddard Space Flight Center, Wallops Flight Facility, Wallops Island, \\ VA, USA \\ ${ }^{8}$ Istituto Nazionale di Geofisica e Vulcanologia (INGV), Rome, Italy \\ ${ }^{9}$ Escuela Centroamericana de Geología, Centro de Investigaciones en Ciencias Geológicas, Red Sismológica Nacional (RSN), \\ Universidad de Costa Rica, San José, Costa Rica
}

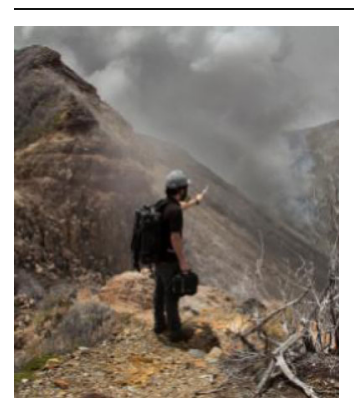

\begin{abstract}
Technology advances in the field of small, unmanned aerial vehicles and their integration with a variety of sensor packages and instruments, such as miniature mass spectrometers, have enhanced the possibilities and applications of what are now called unmanned aerial systems (UAS). With such technology, in situ and proximal remote sensing measurements of volcanic plumes are now possible without risking the lives of scientists and personnel in charge of close monitoring of volcanic activity. These methods provide unprecedented, and otherwise unobtainable, data very close in space and time to eruptions, to better understand the role of gas volatiles in magma and subsequent eruption products. Small mass spectrometers, together with the world's smallest turbo molecular pump, have being integrated into NASA and
\end{abstract} University of Costa Rica UAS platforms to be field-tested for in situ volcanic plume analysis, and in support of the calibration and validation of satellite-based remote sensing data. These new UAS-MS systems are combined with existing UAS flight-tested payloads and assets, such as temperature, pressure, relative humidity, $\mathrm{SO}_{2}, \mathrm{H}_{2} \mathrm{~S}$, $\mathrm{CO}_{2}$, GPS sensors, on-board data storage, and telemetry. Such payloads are capable of generating real time 3D concentration maps of the Turrialba volcano active plume in Costa Rica, while remote sensing data are simultaneously collected from the ASTER and OMI space-borne instruments for comparison. The primary goal is to improve the understanding of the chemical and physical properties of emissions for mitigation of local volcanic hazards, for the validation of species detection and abundance of retrievals based on remote sensing, and to validate transport models.

Keywords: Miniature mass spectrometer, In-situ gas analysis, Harsh environment, Unmanned aerial system, Validation and calibration, Remote sensing comparison, Volcanic plume analysis, Volcanic monitoring, Airborne instrumentation, Volcanic emissions analysis

Received: 10 October 2014/Revised: 20 November 2014/Accepted: 22 November 2014/Published Online: 15 January 2015 


\section{Introduction}

$\mathrm{T}$ he National Aeronautics and Space Administration (NASA) conducts regular missions and campaigns to study Earth's atmospheric chemistry. These data sets are used to understand trends in tropospheric gases and their relation to climate change, determine air quality and emissions standards, and issue volcanic activity warnings to the air traffic control system. To expand NASA's capability to generate scientifically proven data to improve their transport and forecast models, the next generation of airborne missions requires miniaturized instruments that can measure chemical composition of gases, relative humidity, pressure, wind speed, and temperature mapped to specific geo-referenced locations. Therefore, NASA's Earth Science missions have a need for small, integrated instrument payload packages for in situ measurements of key atmospheric parameters in harsh environments such as volcanic plumes.

Volcanologists have demonstrated that changes in gas emission, typically molecules from 1 to $100 \mathrm{Da}$ [1], can provide early warning of hazardous volcanic activity [2]. Sampling of these indicator gases, however, must often be performed in close proximity to the fumarolic vents. Several researchers have deployed networks of ground-based sensors [3] to monitor changing volcanic activity, but often new activity starts at some distance from a previous eruption, limiting the effectiveness of fixed instrumentation for continuous monitoring. Satellite remote sensing is an alternative that can often be useful [4-6] but spatial resolution, spectral calibration, and cloud coverage offer many challenges as well. An airborne multigas sensor suite that can be flown at low altitude to obtain a 3-D chemical map of a volcanic plume, as well as provide suitable calibration and validation of atmospheric data for satellitebased remote sensing instruments, addresses some of these issues. The mass spectrometer is the most powerful and versatile chemical analyzer currently used for research. The benefits of using mass spectrometry (MS) for in situ volcanic monitoring have been discussed previously [1]. It offers multiple determinations of chemical species, together with a large dynamic range of concentrations, from less than one part per million to $100 \%$ concentration. A mass spectrometer can perform both qualitative and quantitative analysis of many gasphase species present, with sufficient dynamic range to detect even very minor components, making this analytical method a good candidate to achieve continuous volcanic gas-monitoring.

With the multiple advancements in mass analyzers, pumping technology, faster electronics, and high-pressure ion detectors, there has been a strong interest in developing complete MS systems that are small in size, weight, and power consumption [7] making it possible to integrate a small mass spectrometer into an unmanned aerial system (UAS). To date, this capability has not been achieved for small UAS platforms. Mass spectrometers have as yet only been integrated into manned aircraft [8] and relatively large and expensive drones such as Global Hawk [9, 10] because of the size of the required instruments and associated auxiliary components such as gas analyzers and vacuum systems.
Using Costa Rican volcanoes as a natural laboratory, the University of Costa Rica as host institution, in collaboration with four NASA Centers: the Jet Propulsion Laboratory (JPL, Lead), the Ames Research Center (ARC), the Goddard Space Flight Center-Wallops Flight Facility (GSFC-WFF), and the Kennedy Space Flight Center (KSC), plus two US companies (INFICON Inc. and CREARE LLC) are together engaged in an initiative to develop field-deployable unmanned airborne small-size (UAS) low-weight, and low-power-consumption, mass spectrometry systems. Such systems, combined with associated multi-instrument packages, will enable the capability to perform in situ volcanic gas flux monitoring and composition analysis in conjunction with orbital observations and state-of-the-art models of plume transport and chemistry. These data help us to better understand the role of such volatiles in magma and subsequent eruption products, as well as the roles they may play in affecting regional and global environments. The overall objective is to better understand how volcanoes work, and specifically to better constrain estimates of persistent background and episodic eruptive trace gas (e.g., $\mathrm{SO}_{2}$ and others) and carbon dioxide emissions. The specific calibration and validation application using small UAS has been described in a recent Geological Society of London journal paper [11]. The current article focuses on the MS systems integration to UAS platforms together with other peripheral and complementary airborne tested sensor package.

\section{Background}

Over the past 20 years, several members of this research team have been working to provide complementary geochemical gas data measurements using mass spectrometry to help monitor and understand volcanic activity. Diaz et al. [12] started to implement mass spectrometry to study gaseous emission in volcanoes and developed a miniature (2-cm radius) doublefocusing magnetic sector mass analyzer as part of a Ph.D. thesis [13] at the University of Minnesota and implemented it into the portable double focusing (P-CDFMS) system to sample fumaroles at several US and Costa Rica volcanoes [14]. The system weighed $8.2 \mathrm{~kg}$ and consumed $144 \mathrm{~W}$ of power and was easily hand-carried for field deployment. It was further tested for space launch applications at the Hazard and Gas Detection Laboratory (HGDL) at NASA Kennedy Space Center (KSC) in 2000 [15]. The CDFMS core technology was patented [16] and licensed for commercialization to Mass Sensors Inc. and later sublicensed to INFICON Inc.

In 2002, NASA's HGDL in collaboration with the University of Costa Rica (UCR) developed an in situ MS-based gas analyzer [7] using a commercial off the shelf small quadrupole mass spectrometer combined with on board autonomous calibration and GPS for geo-referenced and calibrated chemical composition. The airborne volcanic emissions mass spectrometer (AVEMS) was deployed and flight- tested over active volcanoes from 2003 to 2006 on board the NASA WB-57 highaltitude research manned aircraft and on board a Cessna 206 
Stationair aircraft providing the first in situ, NIST-traceable, 3-D, quantitative chemical plot of gaseous volcanogenic activity from several volcanoes in Costa Rica [17]. AVEMS has a size of $82,000 \mathrm{~cm}^{3}$ and mass of $32 \mathrm{~kg}$; it can only be deployed on a relatively large manned airborne platform, which restricts its use in active volcanic eruption environments, where high risk because of the presence of ash clouds and acidic gases (e.g., $\mathrm{SO}_{2}, \mathrm{HCl}$, HF) demands the use on UAV.

A smaller version of the AVEMS named utilization of lightweight in situ sensors and remote sensing to study active volcanic emissions sites (ULISSES), was developed in 2008 with the same commercial MS and GPS sensor used in AVEMS but with lighter supporting components, and without on-board autonomous calibration. It had a volume of 21,000 $\mathrm{cm}^{3}$, weight of $10 \mathrm{~kg}$, and $80 \mathrm{~W}$ of power consumption, and was deployed in 2009 and 2010 into Turrialba Volcano in Costa Rica before and after its eruption in January of 2010 [18]. The field deployments to Turrialba Volcano, both ground and airborne, demonstrated its usefulness to characterize the volcanic gaseous emission concentrations in harsh environment conditions with two key achievements: (1) confirmation of helium increase presence after the eruption, and (2) airborne MS measurements of $\mathrm{SO}_{2}$, allowing the possibility of correlating in situ data with satellite remote sensing measurements from OMI and ASTER spaceborne remote sensing instrument. The ULISSES system was developed to demonstrate a path for single-person use on the ground and for its later integration into small unmanned aircraft vehicles (UAV), targeted to correlate in situ ground data to remote sensing satellite base data for calibration and validation purposes [19], but it had limitations in terms of scan speed, ion sensitivity, pumping system requirement, and overall size and weight. Thus, a new mass analyzer and pumping system was needed to develop a full UAS-MS system in addition to finding an appropriate UAV to carry this payload.

In 2009, three NASA centers: Ames Research Center (ARC), Goddard Space Flight Center-Wallops Flight Facility (GSFC-WFF), and the Jet Propulsion Laboratory (JPL) were added to the collaboration to establish expertise in UAV and remote sensing applications. The expanded group focused on using small airborne UAV platforms, with a mass spectrometer and complementary chemical and meteorological sensors on board, to create an integrated single, low altitude, harsh environment system for in situ volcanic plume gas analysis. In support of this concept, with NASA (Pieri, PI) and UCR support, a yearly deployment of small UAVs and tethered balloons was established to test different instrument packages [20].

In 2013, after searching different possible options to fulfill the hardware needs, INFICON Inc. with their small mass spectrometers for residual gas analysis and CREARE LLC with their unique and very small turbo molecular pump, joined the collaboration, providing a way to close the hardware gap to develop a UAS-MS system targeted to volcanic monitoring [21].

\section{Experimental and Methods}

Figure 1 illustrates the target application for UAS on volcanic plume monitoring as first envisioned by Dr. Pieri at JPL. The strategy makes use of an integrated network of different unmanned airborne platforms (to be coordinated with observations by on-orbit assets as available), with different capacities and payloads, so a complete real-time picture of volcanic emissions is possible. Calibration and validation of satellite data are achieved by comparing in situ data and remote sensing data. This approach provides a path to improve the accuracy of volcanic eruption ash and gas concentration retrievals from orbital data, and improvement of trajectory and ash concentration models for the prediction of airborne hazards to aviation [10].

Space and airborne data can be correlated with existing, traditional ground-based volcanic monitoring networks, such as seismometers, tiltmeters, in-ground gas monitors, and nearfield remote sensing instruments (e.g., MiniDOAS, UV, IR, FTIR cameras). Such a comprehensive approach provides a more precise way to assess the stage of current activity at a given volcano. The goal is that by synergistic use of such data, volcanic eruption forecasts and potential hazard assessments can be substantially improved.

Two different UAS-MS systems are being developed to be integrated into the different UAV options currently available to the team. Each system has a unique set of requirements and features, targeted to match the airborne platform with which it will be deployed. Each UAS-MS payload consists of:

(1) A small commercial mass analyzer for bulk and trace gas analysis

(2) A miniaturized low-mass, low-power turbo molecular/ scroll vacuum pumping system

(3) A small, multi-parameter battery powered sensor suite, called MiniGas, which consists of $\mathrm{SO}_{2}, \mathrm{CO}_{2}$, and relative humidity sensors, GPS, temperature, pressure integrated with embedded micro PC control system, and telemetry system

By combining the UAV, small mass spectrometer, vacuum system, and MiniGas technologies, a new capability for atmospheric analysis and volcanic plume monitoring is possible using the mass spectrometer as the core of a versatile in situ research data acquisition package. The deployment of such technology improves the current capabilities to detect, analyze, monitor, model, and predict hazards presented from active and impending volcanic eruptions. The next sections describe each one of these components.

\section{UAV Platforms}

The small UAV platforms that have been selected for the deployment of the UAS-MS systems are: the SIERRA UAS (NASA ARC), the VECTOR WING 500 (University of Costa 
Rica), and the Allsopp Helikite Aerostat (NASA GSFC-WFF; JPL).

The sensor integrated environmental remote research aircraft (SIERRA) is a $\sim 250 \mathrm{~kg}$ carbon composite UAS that can perform remote sensing and atmospheric sampling missions in inaccessible regions: over mountain ranges, the open ocean, or the Arctic/Antarctic [22]. The airframe was designed by the US Naval Research Laboratory and the flight system was developed at NASA's Ames Research Center. The aircraft has a single 28-kW engine in a pusher configuration enabling unobstructed air sampling from the nose, and maintains a relatively low cruise speed of $100 \mathrm{~km} / \mathrm{h}$. The SIERRA is well suited for precise and accurate data collection missions with the capability to carry up to $45 \mathrm{~kg}$ of scientific instruments providing $1.5 \mathrm{~kW}$ of on-board power. It can fly the unmanned payload for up to $965 \mathrm{~km}$ with 8- to 12 -h endurance, and can operate from short fields without hangar support.

The VECTOR WING 500 is an unmanned flying wing, with an $3.3 \mathrm{~m}$ wingspan, being built in Costa Rica for volcanic gas measurements and capable of waypoint-guided autopilot missions. It has an endurance of $30 \mathrm{~min}$, a payload capacity of $4.5 \mathrm{~kg}$, a maximun flying altitude of $4500 \mathrm{~m} \mathrm{ASL}$ with an airspeed of $10-30 \mathrm{~m} / \mathrm{s}$, with a typical cruise speed of $18 \mathrm{~m} / \mathrm{s}$. Its predecesor, the VECTOR WING 100, developed by Maryland Aerospace for $1 \mathrm{~kg}$ payload and 45-min endurance, has been flight-tested and deployed at Turrialba Volcano for in situ volcanic plume analysis more than 20 times in the last $2 \mathrm{y}$.

The Allsopp Helikite is a commercially available hybrid balloon/kite that uses both buoyancy and aerodynamic lift to fly in a wide variety of wind conditions. Typically, helium is used as the lift gas, and the aerostat systems are typically designed to fly in winds up to $64.3 \mathrm{~km} / \mathrm{h}(18 \mathrm{~m} / \mathrm{s})$. The system includes an electric winch and high-strength line. Instrument power is provided by batteries incorporated as part of the payload, which minimizes the complexity of the winch system compared with tethered systems, which provide power through conductors run in parallel to the restraining line. A Helikite with a volume of 11 or 16 cubic meters is the target platform for carrying the miniature mass spectrometer package.

\section{Mass Spectrometers}

The overall performance of a mass spectrometer depends heavily on the mass analyzer and its associated ion optics.

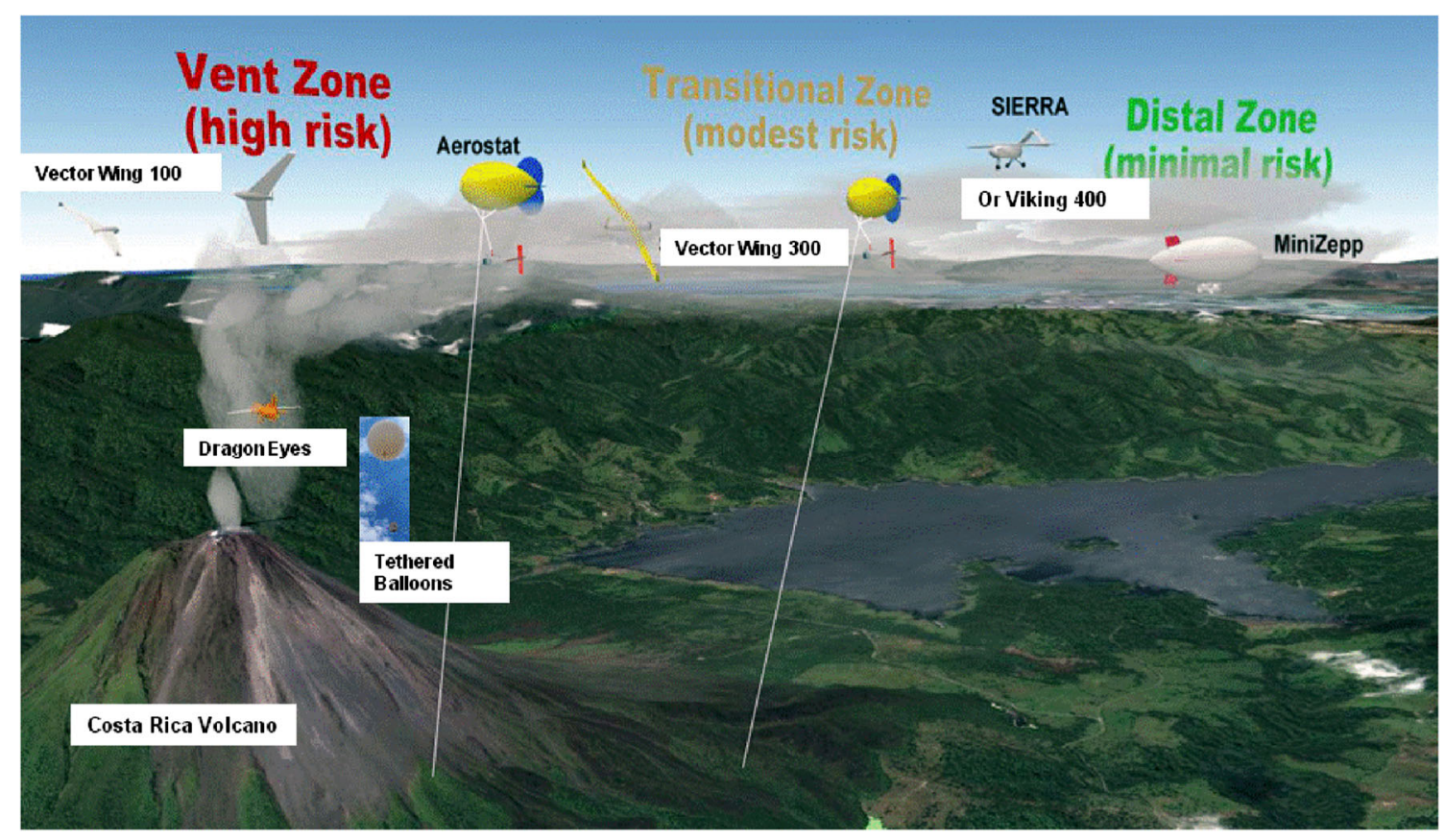

Figure 1. In situ volcanic monitoring multi-platform deployment strategy. As originally conceived, the project objective is to simultaneously deploy into an active or, in some cases, erupting volcano, a series of unmanned aerial systems (UASs) to create a network of airborne observation platforms. This UAS network includes small unmanned aerial vehicles (UAVs-e.g., Dragon Eye, Vector Wing); middle size UAVs (Viking 400, SIERRA, RAVEN-INGV); helium-lifted platforms (tethered balloons, aerostats, helikites, MiniZepp); all integrated with in situ and near-field remote sensing instrumentation and complemented with simultaneous orbital remote sensing and ground-based measurements. The UAS network would operate over and around actively erupting volcanoes in airspace that is too dangerous for manned aircraft. Our goal is to achieve full volcanic plume characterization to assess volcanic conditions, calibrate and validate space-borne remote sensing data, and improve volcanic plume dispersion and forecast models for aviation ash hazard mitigation. Nationally, the airspace is divided into three zones, going from the Vent Zone with high risk and relatively low cost UAS systems been deployed there, the Transitional Zone with mid risk associated and larger UAS systems been deployed there, to the Distal Zone with minimal risk and mid to large UAS system deployed with more expensive and sophisticated equipment 
The appropriate mass analyzer for use in the UAS-MS for in situ airborne studies must have the proper sensitivity (ppm to $100 \%$ concentration), scan speed (below $2 \mathrm{~s} / \mathrm{scan}$ ), and resolution (less than $1 \mathrm{Da}$ ) in the required mass range (1 to $65 \mathrm{Da}$ ) to study volcanic gas emissions. Two commercial mass spectrometers have been selected to develop different UAS-MS systems based on their mass spectrometer characteristics and matching needs of the integrated UAV platform such as payload capacity, volume, and power requirements. Figure 2 shows the two mass spectrome- ters selected: the Transpector MPH small quadrupole mass spectrometer and the Transpector XPR3 miniature quadrupole mass spectrometer, both developed by INFICON Inc.

The Transpector MPH is the newest mass spectrometer from INFICON Inc. This is a third-generation small quadrupole-based mass spectrometer with $6 \times 125 \mathrm{~mm}$ rods, designed for partial pressure vacuum analysis and semiconductor harsh environment process monitoring applications. The MPH provides improved and lighter electronics, increased detection capabilities, and a faster scan rate compared with previous versions, which make it suitable for UAV operations where high sensitivity and fast scan rates are required. Improved serviceability of the Transpector MPH also contributes to its utility in monitoring harsh environments. In terms of hardware, the upper ion source is a field-replaceable precision-aligned assembly that includes the filaments, anode, and repeller so that a filament change will restore performance in harsh environment field deployments where anodes may become contaminated. The electron multiplier + Faraday cup $(\mathrm{EM} / \mathrm{FC})$ detector assembly is a patented design manufactured by Detector Technology Inc., Palmer, MA, USA. The detector has lower noise, higher FC sensitivity, increased EM gain, and longer lifetime compared with previous designs. The EM/FC detector is also field-replaceable.

The second mass spectrometer being used is the Transpector XPR3, which is the latest generation of high-pressure, quadrupole-based process gas analysis mass spectrometers capable of operation in the mTorr vacuum range and is the smallest miniature commercial instrument suited to volcanic gas analysis. The miniature ion source and quadrupole can operate from UHV to $20 \mathrm{mTorr}$, and a specially designed electron multiplier (EM) will operate up to 10 mTorr. The XPR3 is well suited for portable mass spectrometers when paired with a small turbo pump (e.g., Pfeiffer Vacuum's TPD 11 or Creare LLC MDP).

The Transpector MPH electronics are restriction of hazardous substances (RoHS)-compliant and have several advantages over previous generations: a $36 \%$ size reduction $(12.1 \times 11.5 \times$

\section{(a)}
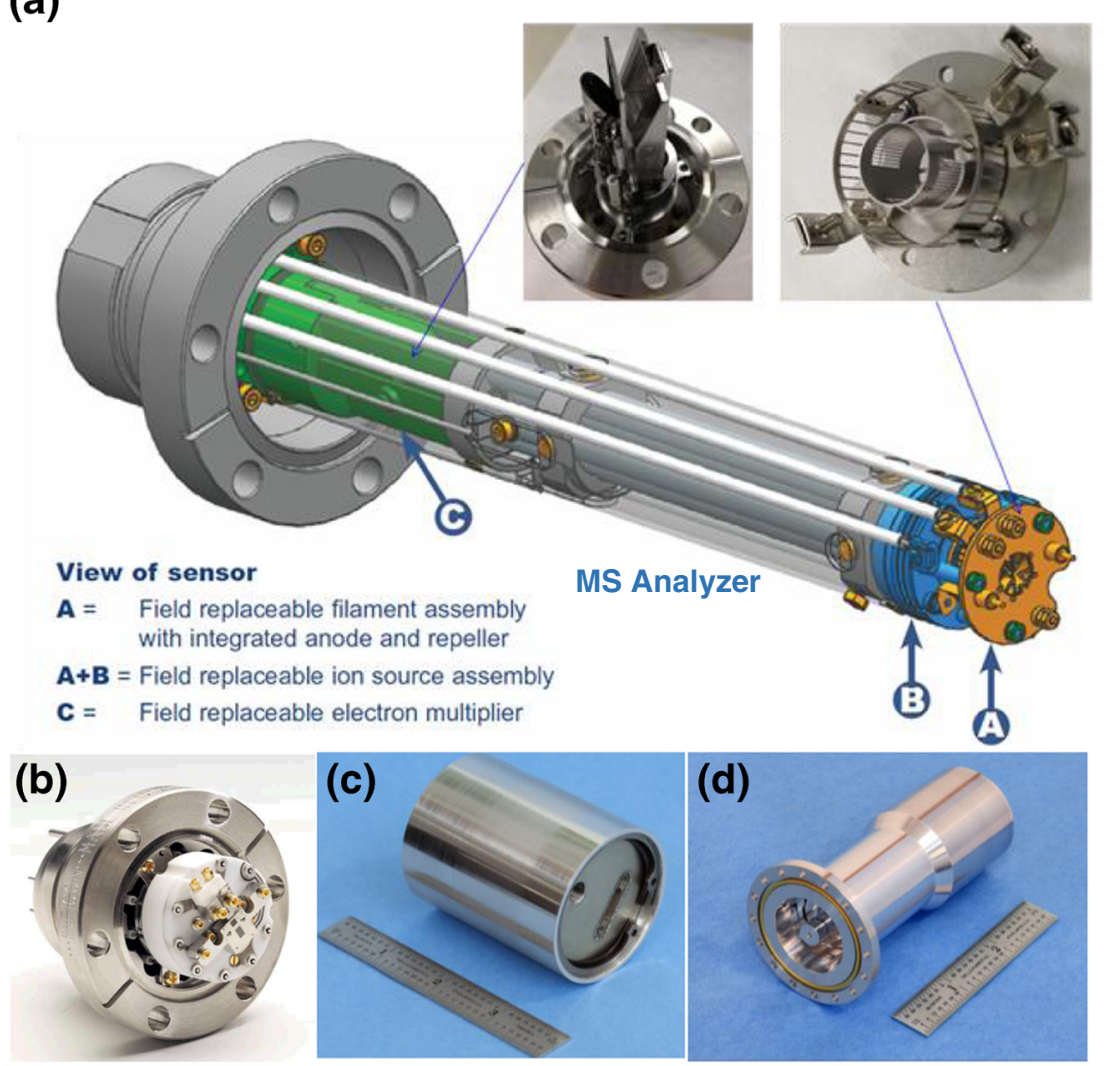

Figure 2. Spectrometers and vacuum components. (a) High performance $125 \mathrm{~mm}$ rods Transpector MPH quadrupole mass spectrometer with field replaceable filament assembly, ion source, and EM/FC detector; (b) miniature $18 \mathrm{~mm}$ rods Transpector XPR3 quadrupole mass spectrometer for mTorr pressure operation; (c) Miniature turbo molecular drag pump (MDP); (d) miniature scroll pump 
$17 \mathrm{~cm}), 40 \%$ weight reduction $(1.4 \mathrm{~kg})$, faster data rates $(<2 \mathrm{~ms} /$ measurement), and improved stability are the key improvements most useful for harsh environment applications. The data rate increase was achieved with a faster $\mathrm{rf} / \mathrm{DC}$ power supply that controls ion filtering in the quadruple and a new galvanically isolated electrometer. Fewer stored charges in the electrometer reduce the delay time out of reset and, therefore, improves the duty cycle for fast measurement times. The Transpector MPH data rates are more than an order of magnitude faster than those of previous generations. The electrometer is also less affected by changes in ambient temperature (operating range $0-50^{\circ} \mathrm{C}$ ). The power requirements, however, have changed little from previous generations (20-30 V input, $20 \mathrm{~W}$ typical power). The Transpector MPH can be controlled using INFICON's FabGuard Suite of software or by using any programming language (e.g., Python or $\mathrm{C}++$ ) and the built in web application programming interface (API). The web API uses JSON over HTTP using TCP/IP protocols. The Transpector XPR3 electronics are based on the Transpector 2 platform and are, therefore, larger $(14.3 \times 12.4 \times 17.5 \mathrm{~cm})$ and heavier $(2.3 \mathrm{~kg})$ than the Transpector MPH but is being re-engineered to reduce total weight to just over $1 \mathrm{~kg}$. The power requirements are similar to the Transpector MPH but the communication is serial (RS-232 or RS-485). The Transpector XPR3 can be controlled using INFICON's FabGuard Suite of software or by any other programming language using serial commands. Table 1 specifies the different characteristics of the two mass spectrometers being used in the UAS-MS systems.

\section{Vacuum System}

The preliminary vacuum system design is comprised of two major components - the high vacuum and the low vacuum subsystems, each optimized for a particular vacuum regime. The system as a whole represents a very substantial reduction in mass, volume, and power consumption over commercially available units. The high-vacuum pump (Figure 2c) is a turbo molecular drag pump (MDP) developed by Creare for NASA [23]. This is the smallest pump of its kind ever developed and has already demonstrated outstanding performance and reliability. The Sample Analysis at Mars (SAM) instrument on board the Mars Science Laboratory (MSL) Curiosity Rover contains two turbomolecular pumps developed by Creare that use similar technology to the one built for the UAV-MS system [24]. The roughing pump is a miniature scroll pump that Creare is developing for portable MS applications under Department of Homeland Security (DHS) funding [25].

The miniature MDP weighs $150 \mathrm{~g}$ and is $8.4 \mathrm{~cm}$ long $\times$ $3.4 \mathrm{~cm}$ i.d. At its nominal operating speed of $200,000 \mathrm{rpm}$, the pump consumes about $1.5 \mathrm{~W}$ of power when discharging to 1 Torr. The measured volumetric flow rate (pump speed) is in excess of $5 \mathrm{~L} / \mathrm{s}$, and the compression ratio for nitrogen and oxygen is greater than $10^{7}$. By careful attention to motor design, a design life in excess of $1 \mathrm{y}$ was achieved, and over 4 mo of nearly continuous operation has been demonstrated. The miniature scroll pump has a mass less than $250 \mathrm{~g}$ and

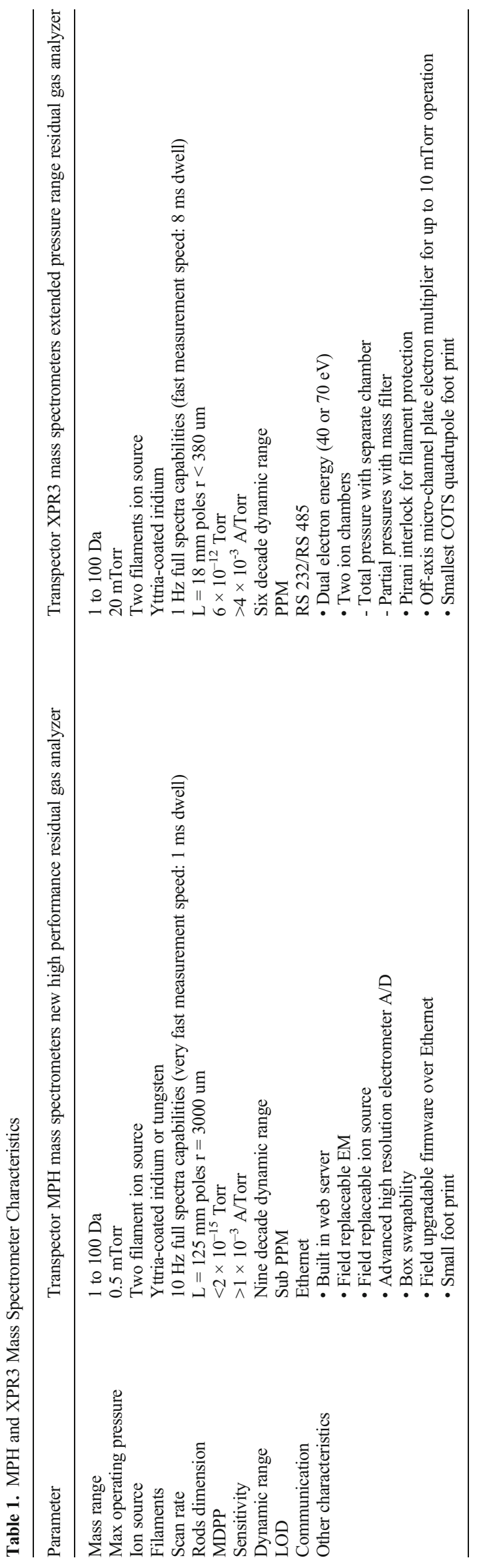



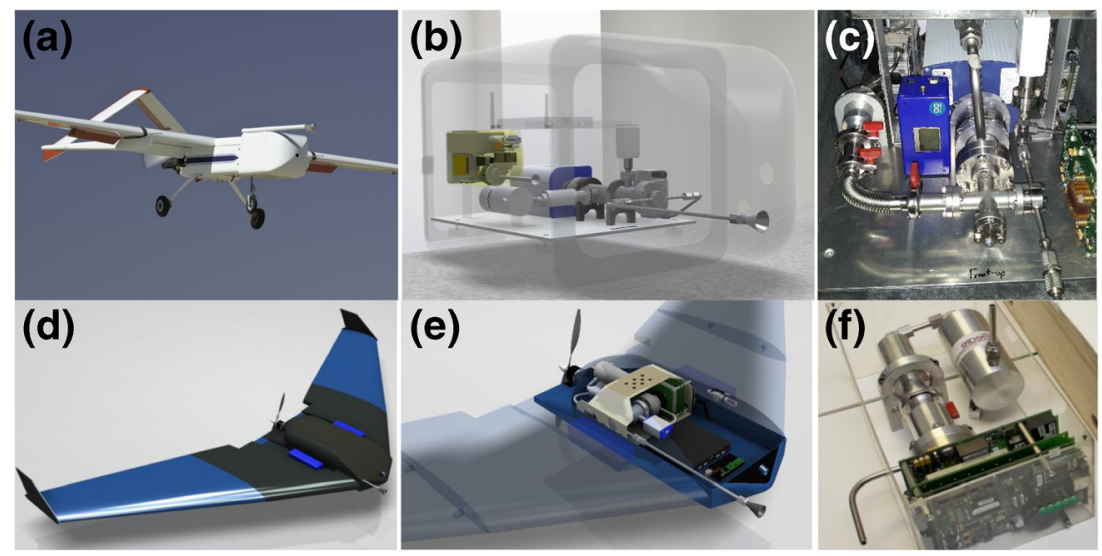

Figure 3. UAS-MS payload design and integration. (a) NASA SIERRA UAV in operation with payload instrumentation bay in the front of the aircraft (nose); (b) 3D engineering design of UAS-MS-MPH system inside the SIERRA nose with main components fully assembled: MiniGas at left, MPH MS on the back, CREARE MPD and Scroll pump in the middle, sample delivery system in the front, and embedded Fit PC on top; (c) Initial integration of same UAV-MS-MPH components inside the SIERRA nose, ready for flight testing; (d) VECTOR 500 UAV from UCR 3D design with payload instrumentation bay embedded into the wing-fuselage; (e) 3D engineering design of UAS-MS-XP3 system inside the VECTOR WING 500 payload bay with main components fully assembled: MPH MS on the right, CREARE MPD, and scroll pump in the back, sample delivery system in the left, and embedded Fit PC on front; (f) initial integration of UAV-MS-XPR3 components inside a UAV payload bay showing a very compact and light configuration ready for flight test. Both systems are powered by a $24 \mathrm{~V}$ LIPO battery

power consumption less than $5 \mathrm{~W}$. The pump achieves significant mass reduction (two to five times) and size savings (two to three times) over commercially available units by optimizing the pump operation to fit the needs of the MS.

Finally, a third pump, a KNF 83.3, is used for sample delivery and inlet to mass spectrometer bypass to lower the pressure before entering the MS to 10 Torr using a critical orifice. A second critical orifice for continuous direct sample analysis is used as inlet to the mass spectrometer, achieving the optimal vacuum level.

\section{UAS-MS Payloads}

The various UAS-MS system layouts conform to the payload volume of each targeted UAV as shown in Figures 3. The small KNF diaphragm pump draws sample gas in a continuous stream into a chamber in front of the mass spectrometer inlet. The chamber is maintained at a constant pressure using a combination of critical orifices and flow controller. The mass spectrometer inlet samples the gas stream orthogonally through a critical orifice to ensure rapid response time. The miniature MDP maintains the mass spectrometer at the adequate vacuum level for operation (typically between $10^{-3}$ to $10^{-5}$ Torr depending on the mass spectrometer) and is backed with the miniature scroll pump or a KNF 84.4 diaphragm pump.

To develop a more complete payload, the UAS-MS system is also combined with the MiniGas payload, which has been flight tested within the Turrialba volcanic plume onboard the VECTOR WING $100 \mathrm{UAV}$ and tethered balloon airborne platforms. It includes temperature, pressure, relative humidity, $\mathrm{SO}_{2}$ and $\mathrm{H}_{2} \mathrm{~S}$ electrochemical sensors, non-dispersing near infrared $\mathrm{CO}_{2}$ sensor, GPS sensor, on-board data storage. and telemetry, generating real time $3 \mathrm{D}$ gas concentration plots of the active volcanic plumes. These auxiliary sensors are readily available sensors that have a long history of use in radiosondes and tethered balloon studies. The MiniGas payload is added to the side of the UAV nose in order to measure the complementary physical parameters as shown in Figure 3. In situ sampling with the MiniGas is achieved by either exposing the sensors to the external atmosphere (passive measurements) or else injecting an airstream into the multi-sensor platform with a very small displacement pump (active measurements) to generate a concentration profile. In addition, a single-board computer (Fit PC3) is used to acquire the mass spectrometer and MiniGas data, store, and transmit the data.

The UAS-MS-MPH depicted in Figure $3 \mathrm{~b}$ and $\mathrm{c}$ is targeted for mid-sized UAVs with payload capabilities from 20 to $50 \mathrm{~kg}$ like the SIERRA (Figure 3a). The UAS-MS-XPR3, shown in Figure $3 e$ and $f$, is suitable for small UAV-based airborne measurements like the VECTOR WING 500 (Figure 3d) and Helikite UAVs with payloads capabilities of 3 to $5 \mathrm{~kg}$.

A ground transportable platform was also developed to serve as a test bed for the MPH and XPR3 mass spectrometers and vacuum system before integration into a variety of UAV payloads. The portable system has the same basic layout as the UAS-MS system inside a Model 1510 Pelican case targeted for field work and ground transport. These cases will also serve as shipping vessels to test sites before integration with the UAV. As an example, Figure 4 shows the UAV-MS-XPR3 ground field test unit at Turrialba Volcano, Miravalles Volcano. and Sofatara Volcano field deployments. The field test payload can be transported as a backpack unit into the active volcano. At the same time, the same MiniGAS system can be partnered with any of two MS units for field and UAV deployments. 


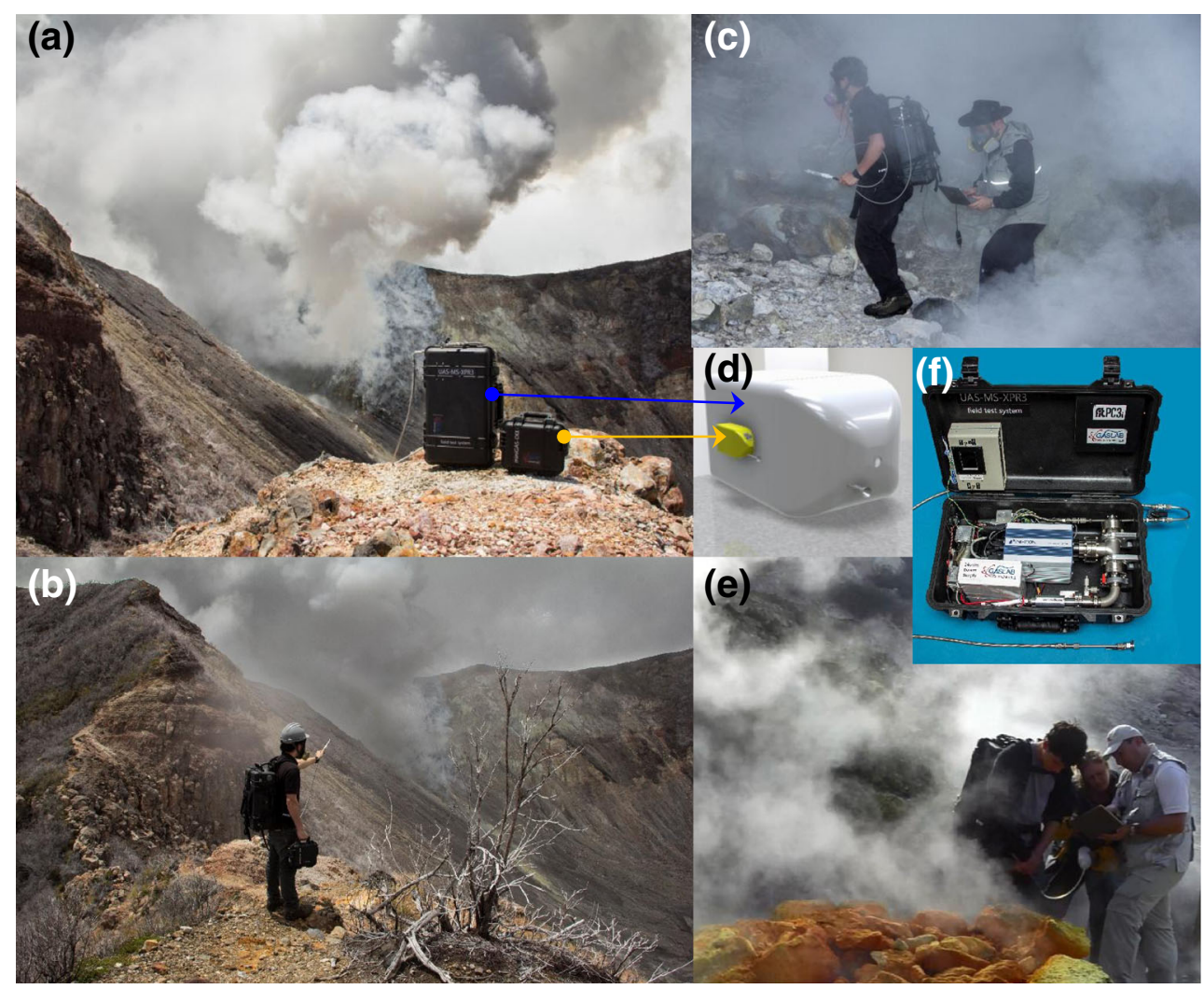

Figure 4. UAS-MS field test system deployments. (a) Turrialba volcano test site with both MiniGas and UAS-MS-MPH field test systems shown at the summit crater. The combined payloads are capable of acquiring geo-referenced trace gas concentration data for a large number of gases with a dynamic range, selectivity, accuracy, and repeatability that only a mass spectrometer can provide. It also measures independently $\mathrm{SO}_{2}, \mathrm{H}_{2} \mathrm{~S}$, and $\mathrm{CO}_{2}$ gas concentrations for cross-referencing, and acquires relative humidity, pressure, and temperature data. These capabilities are very useful for a large number of environments for both NASA and commercial applications. (b) Both systems are contained and transported in sealed Pelican cases, and can be easily backpackand hand-carried to the volcano for field evaluation before they are integrated into the SIERRA UAV payload nose as depicted in (d). Three weeks after this picture was taken, Turrialba volcano erupted, and a massive collapse greatly enlarged the vent area shown, as active degassing continued. (c) UAS-MPH-XPR3 field test system being deployed into Las Hornillas fumarolic site at Miravalles volcano in Costa Rica and (e) Bocca Grande and Bocca Nuova fumaroles at Solfatara volcano test site in Naples, Italy for volcanic plume emission analysis. (f) Field test system consist of the MPD mini turbo molecular pump, scroll pump, and controller integrated to very small and compact vacuum chamber where the XPR3 mass spectrometer is also attached via 2.75" CF flange. A compact sample delivery system allows the direct sampling of the volcanic gases while maintaining good vacuum inside the vacuum chamber and provides a very fast response time using a small KNF 83.3 bypass pump. The system is powered with $24 \mathrm{~V}$ LIPO battery (white brick on the lower left of the picture)

\section{Results and Discussion}

The MS, vacuum station components, and miniGas payload were integrated into a single UAV-mass spectrometry system and lab-tested with good results. Initial testing of the MPHspectrometer component was conducted using direct gas inlet to verify dynamic range and limit of detection (LOD). Targeted molecular gas species for volcanic plume analysis are: $\mathrm{He}, \mathrm{H}_{2}$, $\mathrm{H}_{2} \mathrm{O}, \mathrm{N}_{2}, \mathrm{O}_{2}, \mathrm{Ar}, \mathrm{CO}_{2}, \mathrm{SO}_{2}$, and $\mathrm{H}_{2} \mathrm{~S}$. Three calibration gases were used: Zero (0 ppmv UHP Ar), Test (1000 ppmv $\mathrm{H}_{2}, \mathrm{He}$, $\mathrm{O}_{2}, \mathrm{~N}_{2}, \mathrm{CO}_{2}$ in Ar background, and Span (10,000 ppmv $\mathrm{H}_{2}$, $\mathrm{He}, \mathrm{O}_{2}, \mathrm{~N}_{2}, \mathrm{CO}_{2}$ in Ar background). The raw mass spectrometer data for the measurements taken are shown in Figure 5a. The spectra demonstrated the MPH spectrometer capability to achieve high dynamic range, very good linearity, and sub-ppm limits of detection. Furthermore, the ion signals of the isotopes is presented in Table 2 and show very good agreement with nominal relative abundance.

Each UAV-mass spectrometry system was calibrated in the laboratory prior to each field deployment using a compact sample delivery system with flow and pressure control and three certified NIST traceable calibration gas cylinders provided by AIRGAS/PRAXAIR in Costa Rica for zero-test-span calibration points. Calibrated $\mathrm{SO}_{2}$ data taken by the field portable UAV-MS-XPR3 using 0, 5, 20, and 50 ppmv calibrated bottles achieved an LOD of 0.3 ppmv for $\mathrm{SO}_{2}$ at $1 \mathrm{~Hz}$ scanning rate, less than $10 \%$ reading error, and less than $3 \%$ RSD.

The first UAS instrument deployments for volcanic plume characterization were performed from March 2013 to October 2014, using the MiniGas payload and the UAS- 


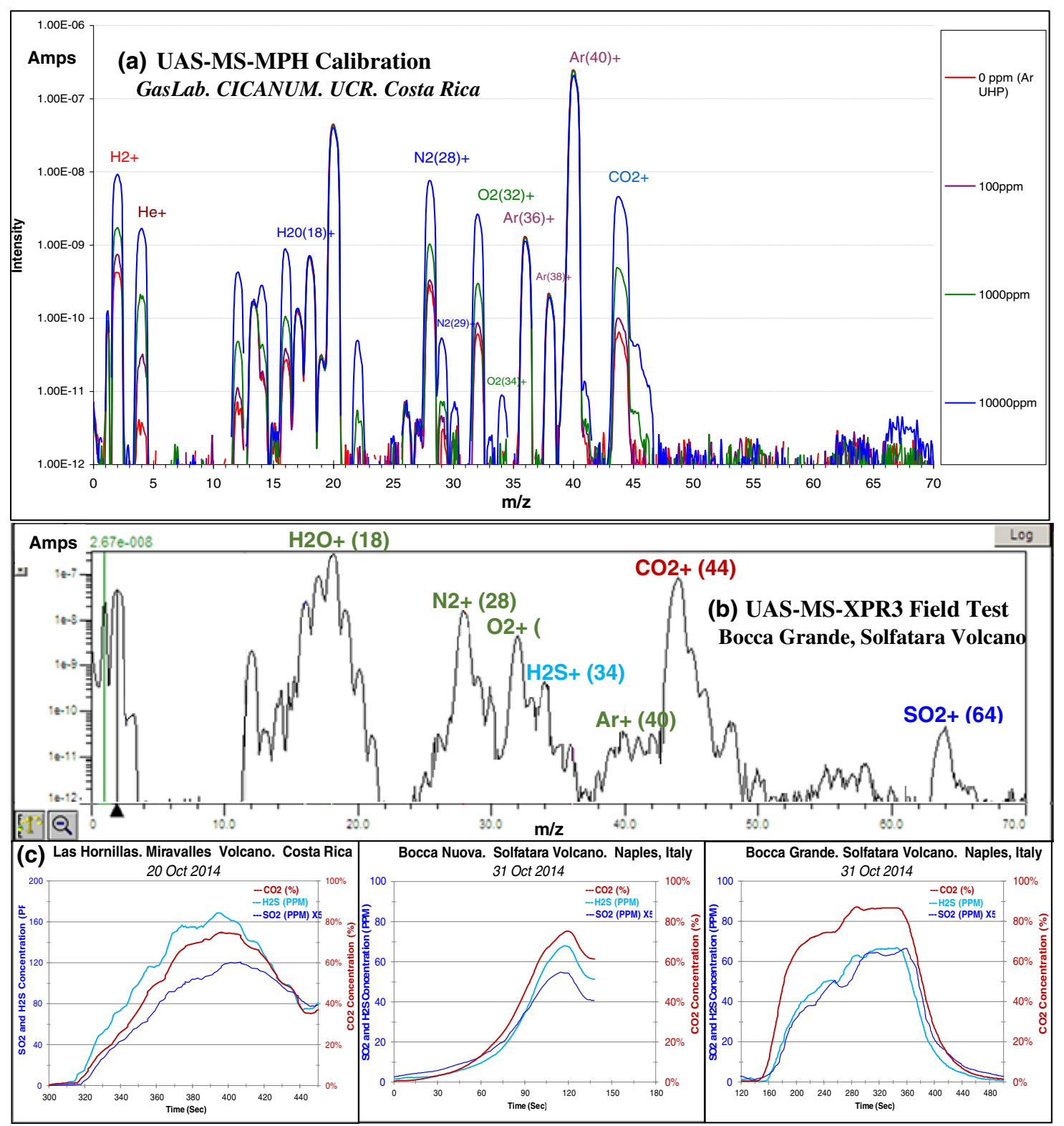

Figure 5. UAV-mass spectrometer field test results. (a) UAS-MS-MPH Lab calibration superimposed spectra for 0 ppmv (red), 100 ppmv (violet), 1000 ppmv (green), and 10,000 ppmv (blue) of calibration gases $\mathrm{H}_{2}, \mathrm{He}, \mathrm{N}_{2}, \mathrm{O}_{2}$, and $\mathrm{CO}_{2}$ in $\mathrm{Ar}_{\text {background a } 1 \mathrm{~Hz}}$ scan rate. (b) UAV-MS-XPR3 field test spectrum of Bocca Grande fumarole at Solfatara volcano, Italy, showing the presence of $\mathrm{H}_{2} \mathrm{O}$ and $\mathrm{CO}_{2}$ as main gases emitted, and revealing the presence of $\mathrm{H}_{2} \mathrm{~S}$ and $\mathrm{SO}_{2}$ as trace gases in tens of ppm concentration besides some air contamination $\left(\mathrm{N}_{2}, \mathrm{O}_{2}\right.$, Ar peaks). (c) In situ direct MS sampling in the calibrated multiple-ion mode of Las Hornillas fumarolic field at Miravalles volcano, data from Bocca Nuova and Bocca Grande fumaroles at Solfatara volcano taken with UAS-MS-XPR3 field test system. Spectra show main volcanic gas to be $\mathrm{CO}_{2}$ (tens of \% levels), $\mathrm{H}_{2} \mathrm{~S}$ and $\mathrm{SO}_{2}\left(10-100\right.$ ppmv). Note: $\mathrm{H}_{2} \mathrm{~S}$ and SO 2 ppm concentrations are referenced to left vertical axis $\left(\mathrm{SO}_{2}\right.$ ion trend is multiplied by 5 to better show values and correlation with other volcanic gases). $\mathrm{CO}_{2}$ concentration in percentage levels are referenced in right vertical axis

Table 2. MPH Mass Spectrometry Testing. Isotope Ratio calculations

\begin{tabular}{|c|c|c|c|c|c|}
\hline \multicolumn{6}{|c|}{ MPH mass spectrometry isotope components } \\
\hline Component & Mass (Da) & MPH MS signal & Signal ratio to main isotope & Relative abundance & $\%$ Error \\
\hline${ }^{14} \mathrm{~N}_{2}$ & 28.006 & 7.57E-09 & 1 & 1 & - \\
\hline${ }^{14} \mathrm{~N}^{15} \mathrm{~N}$ & 29.003 & $5.35 \mathrm{E}-11$ & $0.707 \%$ & $0.371 \%$ & $0.335 \%$ \\
\hline${ }^{16} \mathrm{O}_{2}$ & 31.99 & 2.64E-09 & 1 & 1 & - \\
\hline${ }^{16} \mathrm{O}^{18} \mathrm{O}$ & 33.994 & $8.84 \mathrm{E}-12$ & $0.334 \%$ & $0.200 \%$ & $0.134 \%$ \\
\hline${ }^{36} \mathrm{Ar}$ & 35.97 & $1.12 \mathrm{E}-09$ & $0.535 \%$ & $0.341 \%$ & $0.194 \%$ \\
\hline${ }^{38} \mathrm{Ar}$ & 37.96 & $1.92 \mathrm{E}-10$ & $0.0913 \%$ & $0.0633 \%$ & $0.0281 \%$ \\
\hline${ }^{40} \mathrm{Ar}$ & 39.96 & $2.10 \mathrm{E}-07$ & 1 & 1 & - \\
\hline
\end{tabular}



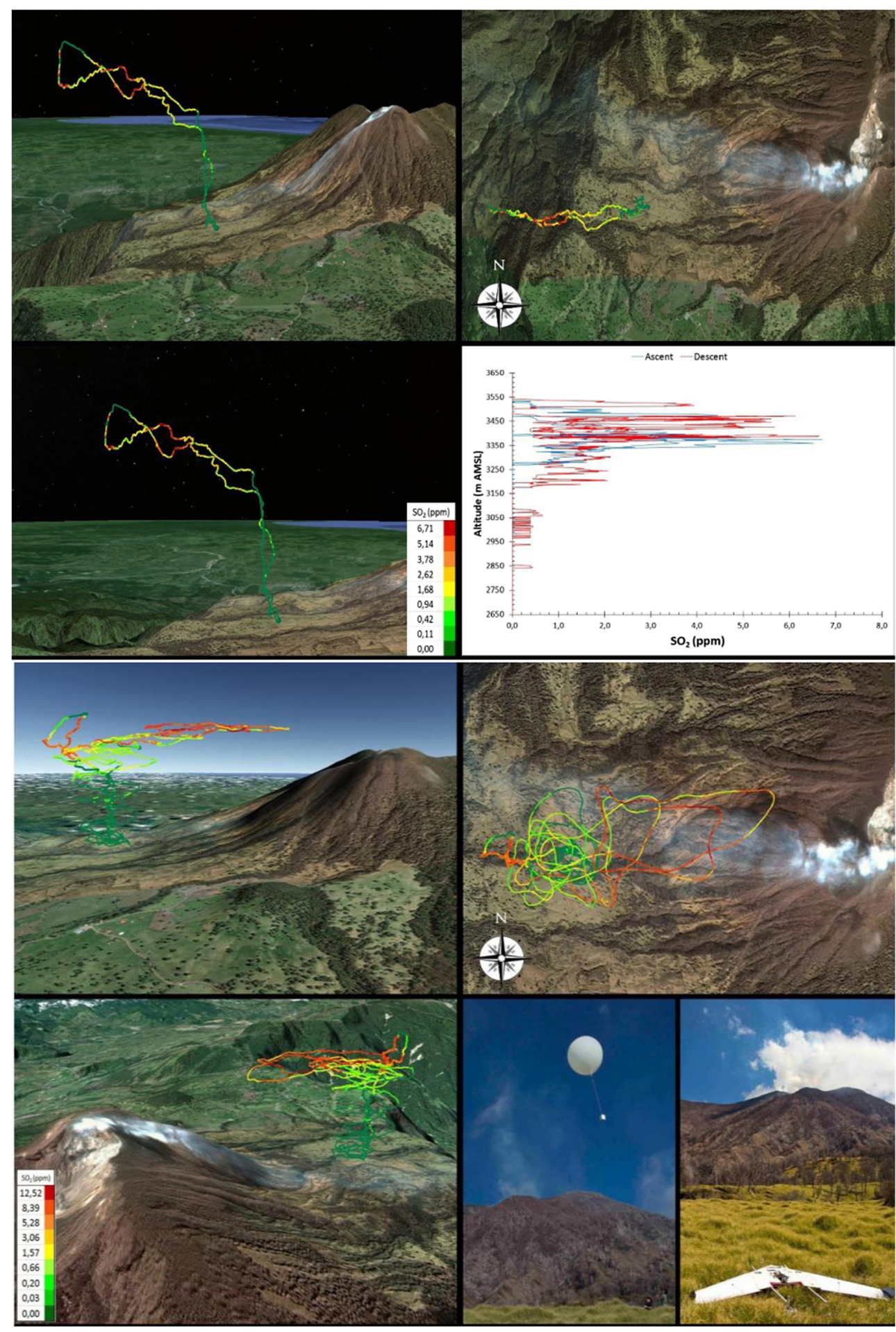

Figure 6. $3 \mathrm{D} \mathrm{SO}_{2}$ concentration plots for UAS flights. Data taken on December 9, 2013 (above) with a tethered balloon and January 23, 2013; and (below) with combined tethered balloon and Vector Wing 100 UAS flights within Turrialba volcano's active plume. Both $3 \mathrm{D} \mathrm{SO} 2$ plots show the UAS intersecting the plume starting at $3200 \mathrm{~m} \mathrm{AMSL}$, maximum at around $3400 \mathrm{~m} \mathrm{AMSL}$, and ending at $3550 \mathrm{~m}$, providing $350 \mathrm{~m}$ plume thickness. $\mathrm{SO}_{2}$ max concentration of $6.7 \mathrm{ppm}$ on December 9 and $12.5 \mathrm{ppm}$ were observed during the UAS test flight. This is the information necessary to improve plume trajectory forecast. In situ UAS data is collected every $16 \mathrm{~d}$ in coincidence of ASTER overpass to correlate with the remote sensing data. The remote sensing data yielded similar concentrations as the ones obtained with the in situ measurements as documented on manuscript "In situ observations and sampling of volcanic emissions with NASA and UCR unmanned aircraft, including a case study at Turrialba Volcano, Costa Rica" from Pieri D, Diaz J.A., Bland G, Fladeland M, et al. Geological Society, London, Special Publication. Sept 25, 2013. doi 10.1144/SP380.13 
MS-MPH and UAV-MS-XPR3 field test systems. Figure 5b shows the full spectra of La Bocca Grande fumarole at Solfatara Volcano in Naples, Italy, taken with the UASMS-XPR3 field test system. Similar deployments were conducted at La Bocca Nuova fumarole at Solfatara Volcano and at the Las Hornillas fumarolic site at Miravalles Volcano, Costa Rica, characterizing the main volcanic gases present (besides water vapor). Figure $5 \mathrm{c}$ shows the concentration obtained at each fumarole site after mass spectrometer ion signal calibration. Las Hornillas fumarole mass spectrometer data show a concentration of $\mathrm{CO}_{2}$ close to $75 \%, \mathrm{H}_{2} \mathrm{~S}$ concentration of $168 \mathrm{ppmv}$, and $\mathrm{SO}_{2}$ concentration of 24 ppmv. La Bocca Grande fumarole mass spectrometer data show a concentration of $\mathrm{CO}_{2}$ close to $86 \%$, $\mathrm{H}_{2} \mathrm{~S}$ concentration of $66 \mathrm{ppmv}$, and $\mathrm{SO}_{2}$ concentration of 13 ppmv. Finally, La Bocca Nuova fumarole mass spectrometer data show a $\mathrm{CO}_{2}$ concentration of $76 \%, \mathrm{H}_{2} \mathrm{~S}$ concentration of $68 \mathrm{ppmv}$, and $\mathrm{SO}_{2}$ concentration of $11 \mathrm{ppmv}$. The UAS-MS-MPH was also deployed to Solfatara Volcano, but the vacuum chamber was damaged during shipping to the site, so it was not possible to test it in this deployment. It will instead be tested early next year at volcanoes in both Costa Rica and Italy.

Figure 6 shows the 3D $\mathrm{SO}_{2}$ concentration plots of the Turrialba Volcano plume taken on December 9, 2013 using a tethered balloon and on January 23, 2013 using the VECTOR WING $100 \mathrm{UAV}$. In situ data concentration is color-coded, with green indicating background concentration levels and red indicating high concentration reading. Red is shown where the platform penetrates the plume, making it possible to estimate plume height and thickness to improve transportation models. Maximum concentrations of 6.7 and $12.5 \mathrm{ppmv} \mathrm{SO}_{2}$ measured by the in situ UAS instrument compared well with concentration estimates retrieved from ASTER multispectral thermal infrared remote sensing data.

\section{Conclusions and Future Development}

The UAS-MS instruments comprise an in situ harshenvironment mass spectrometer-based system designed to be flown on-board UAV platforms and capable of monitoring multi-gas species simultaneously, within a mass range from 1 to $100 \mathrm{Da}$. This system targets volcanic plumes both at ground level and at altitude from unmanned airborne platforms to (1) better assess and understand volcanic eruption precursors without putting the lives of researchers at risk, and (2) better assess fundamental persistent volcanic processes and associated emissions. The current detection limits of the instrument are below 1 ppmv for permanent gases with a typical accuracy of 5\%. The system requires no operator, is rugged, and can operate up to an altitude of $5 \mathrm{~km}$ ASL for up to $1 \mathrm{~h}$. Planned deployments using the VECTOR WING 500, tethered helium balloons and Helikite platforms, in combination with the MiniGas payload provide a way forward to study and visualize gaseous volcanic emissions at close range and relatively low risk. Using such comprehensive laboratory-quality gas sensing instrumentation, despite harsh environmental conditions, permits high quality repeatable correlation between in situ ground/airborne data and remotely sensed satellite data, for calibration and validation purposes.

The upcoming flight testing of a mass spectrometer as part of a full UAS-MS payload is the next step in bringing this technology to an operational level. The US-Costa Rica team will test-fly the UAS-MS-MPH system in the SIERRA UAV at the Ames Research Center early next year in preparation for volcano deployments. In addition, the University of Costa Rica team is in the process of building and flight-testing the VECTOR WING 500 UAV to accommodate the lighter UAS-MS-XPR3 system ( $5 \mathrm{~kg}$ mass) that is slated to be flight-tested in April 2015 within the active plume at Turrialba Volcano as part of the 2015 CARTA joint mission. The focus will be to assess integrated UAS performance in a volcanic plume, including conducting a full inventory of emitted gases, especially as they are related to magma chemistry and in plume heterogeneous chemistry. A particular problem to be addressed in more detail is the dynamic proximal hydrolysis of $\mathrm{SO}_{2}$ and the production of sulfate nanoparticles.

The acquisition of data provided by these mass spectrometer systems is a key step towards a better understanding of geochemical and geophysical phenomena comprising eruptive activity. The combination of accurate, high precision gas measurements with satellite imaging data allows the spatial and temporal mapping of emitted gas distributions at volcanoes, allowing assessment of hazardous conditions through quantitative measurement and qualitative visualization. UAS-MS systems directly facilitate NASA earth science missions by providing a robust and broad spectrum of in situ gas sampling with trace gas analysis capability, combined with temperature, humidity, pressure, position, and, in a near future, particle characterization data for ash-driven volcanic plumes. Such combined instrument package capabilities for in situ airborne data gathering do not currently exist for hazardous and harsh flight environments for use by the atmospheric science or volcanological research communities. The UAS-MS can also be easily adapted to other atmospheric chemistry studies as well as ground measurements through similar airborne campaigns for calibration and validation of satellite-based remote sensing data. One sensing modality that we want to include in a future extension of the instrument package in order to make it even more useful for atmospheric sampling is a particle size sensor for aerosol and ash particle characterization. We are currently working with MSE Inc., whose miniLDV is the world's smallest laser Doppler velocity sensor. The miniLDV probe weighs $250 \mathrm{~g}$ and is packaged in a cylinder of $32 \mathrm{~mm}$ diameter by $165 \mathrm{~mm}$ length. It is capable of measuring velocities in the range of -50 to $600 \mathrm{~m} / \mathrm{s}$ with a specified accuracy of $99.7 \%$ for particles in the range from $1 \mu$ to $1 \mathrm{~mm}$. This sensor 
will seamlessly integrate with the current instrument and will be included in a next generation development of the sensor package.

We believe the current project presents significant advancements in the state of the art of airborne gas measurements, providing an opportunity to collect near-laboratory quality in situ data directly in the field, over a variety of worldwide conditions ranging from relatively benign to operationally difficult.

In summary, a UAS equipped with a small mass spectrometer offers new capabilities that will significantly improve the ability to gather in situ information in the very hazardous environments around and over volcanoes and other atmospheric applications.

\section{Acknowledgments}

The authors thank the ASTER team for acquisition and access to ASTER images. The UCR authors thank the CICANUM Director Ralph Garcia for his support and project coordination with the Dean of Research at University of Costa Rica; to Sara Azofiefa and Yetty Madrigal from the GasLab for their daily help and logistics support of the project. The authors thank Sergio Achi at the CICANUM Electronic lab for his help in troubleshooting the PCBs, and to Victor Rodriguez ("Gato") at the Physics School mechanical shop for machining some of the UAS-MS components.

The authors also thank the Parque Nacional Volcan Turrialba, the Area Conservacion Cordillera Volcanic Central (ACCVC) del Sistema Nacional de Areas de Conservacion (SINAC) del Ministerio de Ambiente y Energia (MINAE), the Direccion General de Aviacion Civil, the Department of Control Aereo del Aeropuerto Juan Santamaria, and the Montero Gutiérrez family from Finca La Central del Volcan Turrialba for their support in authorizing the UAV and tethered balloon flights into the Turrialba volcano plumes, and to Tony Lachner from Volcan Turrialba Lodge for his help on each one of the field deployment for the CARTA Missions. They also thank the Red Sismologica Nacional (RSN) and the Observatorio Vulcanológico y Sismológico de Costa Rica (OVSICORI) for their logistics support during the Turrialba Volcano and Miravalles Volcano ground site testing in Costa Rica, the Istituto Nazionale di Geofisica e Vulcanologia (INGV), and in particular the personnel of Centro Nazionale Terremoti and Osservatorio Vesuviano Sections for their help, support and invitation to Solfatara Volcano ground test in Italy.

The authors acknowledge the Dean of Research at the Universidad de Costa Rica for the financial support of part of this project under grant 915-A9-091. This research was also carried out, in part, under contract to NASA at the Jet Propulsion Laboratory of the California Institute of Technology in Pasadena.

\section{References}

1. Diaz, J.A., Giese, D.F., Gentry, W.R.: Mass spectrometry for in situ volcanic gas monitoring. Trends Anal. Chem. 21(8), 498-514 (2002)

2. Aiuppa, A., Federico, C., Giudice, G., Giuffrida, G., Guida, R., Gurrieri, S., Liuzzo, M., Moretti, R., Papale, P.: The 2007 eruption of Stromboli volcano: insights from real-time measurement of the volcanic gas plume $\mathrm{CO}_{2} / \mathrm{SO}_{2}$ ratio. J. Volcanol. Geotherm. Res. 182(3/4), 221-230 (2009)

3. Salerno, G.G., Burton, M.R., Oppenheimer, C., Caltabiano, T., Randazzo, D., Bruno, N., Longo, V.: Three years of $\mathrm{SO}_{2}$ flux measurements of Mt. Etna using an automated UV scanner array: comparison with conventional traverses and uncertainties in flux retrieval. J. Volcanol. Geotherm. Res. 183(1/2), 76-83 (2009)

4. Kearney, C.S., Dean, K., Realmuto, V.J., Watson, I.M., Dehn, J., Prata, F.: Observations of $\mathrm{SO}_{2}$ production and transport from Bezymianny volcano, Kamchatka, using the moderate resolution infrared spectroradiometer (MODIS). Int. J. Remote Sens. 29(22), 6647-6665 (2008)

5. Pieri, D., Abrams, M.: ASTER watches the world's volcanoes: a new paradigm for volcanic observations from orbit. J. Volcanol. Geotherm. Res. 135(1/2), 13-28 (2004)

6. Realmuto, V.J., Abrams, M.J., Buongiorno, M.F., Pieri, D.C.: The use of multispectral thermal infrared image data to estimate the sulfur-dioxide flux from volcanoes - a case study from Mount Etna, Sicily, July 29, 1986. J. Geophys. Res. Solid Earth 99, 481-488 (1994)

7. In: Proceedings of the 9th Workshop on Harsh-Environment Mass Spectrometry. Harsh-Environment Mass Spectrometry Society (HEMS). ISBN: 9781629935317. 1, pp. 1-89 St. Pete Beach, Florida (2013)

8. Arkin, C.R., Griffin, T.P., Diaz, J.A., Follistein, D.W., Curley, C.H., Floyd, D.P., Naylor, G.R., Haskell, W.D., Blalock, M., Adams, F.W.: A small mass spectrometer system for in situ gas analysis. Trends Anal. Chem. 23(4), 322-330 (2004)

9. Brown, S.T., Lambrigtsen, B., Denning, R.F., Gaier, T., Kangaslahti, P., Lim, B.H., Tanner, A.B..: The high-altitude MMIC sounding radiometer for the global hawk unmanned aerial vehicle: instrument description and performance: geoscience and remote sensing. IEEE Trans. 49(9), 3291$3301(2011)$

10. Braun S.A., Kakar R., Zipser E., Heymsfield G., Albers C., Brown S., Durden S. L., Guimond S., Halverson J., Heymsfield A., Ismail S., Lambrigtsen B., Miller T., Tanelli S., Thomas J., Zawislak J.: NASA's Genesis and Rapid Intensification Processes (GRIP) field experiment. Bull. Am. Meteorol. Soc. 94(3), 345-363 (2013)

11. Pieri D., Diaz J.A., Bland G., Fladeland M., Madrigal Y., Corrales E., Alegria O, Alan A., Realmuto V., Miles T. and Abtahi A. : In situ observations and sampling of volcanic emissions with NASA and UCR unmanned aircraft, including a case study at Turrialba volcano, Costa Rica. Geol. Soc. Lond. Spec. Publ. 380, 321-352 (2013)

12. Diaz, J.A., Giese, C.F., Gentry, W.R.: Sub-miniature ExB sector-field mass spectrometer. J. Am. Soc. Mass Spectrom. 12(6), 619-632 (2001)

13. Diaz, J.A.: Sub-miniature double-focusing mass spectrometer for in situ environmental monitoring and application to volcanic gaseous emissions. $\mathrm{Ph} . \mathrm{D}$. Thesis, University of Minnesota (1999)

14. Diaz, J.A., Gentry, W.R., Giese, D.R.: Portable double focusing sector field mass spectrometer system for field gas monitoring. Field Anal. Chem. Technol. 5(3), 156-167 (2001)

15. Arkin, C.R., Griffin, T.P., Ottens, A.K., Diaz, J.A., Follistein, D.W., Adams, F.W., Helms, W.R.: Evaluation of small mass spectrometer systems for permanent gas analysis. J. Am. Soc. Mass Spectrom. 3, 1004 $1012(2002)$

16. Diaz, J.A., Gentry, W.R., Giese, C.F.: Double focusing mass spectrometer apparatus and methods regarding same. Regents of the University of Minnesota, Assignee, US Patent 6,501,074, Dec 31 (2002)

17. Griffin, T.P., Diaz, J.A., Arkin, C.R., Soto, C., Curley, C.H., Gomez, O.: Three-dimensional concentration mapping of gases using a portable mass spectrometer system. J. Am. Soc. Mass Spectrom. 19, 1411-1418 (2008)

18. Diaz J.A., Pieri D., Arkin C. R., Gore E., Griffin T. P., Fladeland M., Bland G., Soto C., Madrigal Y., Castillo D., Rojas E. and Achí S.: Utilization of in situ airborne MS-based instrumentation for the study of gaseous emissions at active volcanoes. Int. J. Mass Spectrom. 295(3), 105$112(2010)$

19. Pieri, D.C.: Precursor monitoring, eruption detection, and aerosol tracking: integrating in situ and remote sensing techniques. In: Proceedings of the JUST Workshop on the Utilization of Remote 
Sensing Tech to Natural Disaster Reduction. Tsukuba, Japan October 26-28 (1998)

20. Pieri, D.C., Diaz, J.A., Bland, G., Fladeland, M.: Airborne ash hazards: in situ calibration and validation of remotely sensed data and models. Oral presentation, poster presentation, abstract. In: Proceedings AGU Chapman Conference Volcanism and the Atmosphere, Selfoss, Iceland, pp. 10-15, June (2012)

21. Diaz, JA.: Development of unmanned aerial vehicle mass spectrometer (UAV-MS) system for calibration and validation of satellite remote sensing data using in situ volcanic plume analysis. Presented at: 9th HarshEnvironment Mass Spectrometry Workshop, St. Pete Beach, FL. September $15-18$ (2013)

22. Fladeland, M., Sumich, M., Lobitz, B., Kolyer, R., Herlth, D., Berthold, R., Bland, G.: The NASA SIERRA science demonstration programme and the role of small-medium unmanned aircraft for earth science investigations. Geocarto Int. 26(2), 157-163 (2001)

23. Sorensen, P.H., Kline-Schoder, R.: Miniature vacuum system for portable instruments. Presented at: 7th Harsh-Environment Mass Spectrometry Workshop, Santa Barbara, CA, September 21-24 (2009)
24. Mahaffy P.R., Webster C.R., Cabane M., Conrad P.G., Coll P., Atreya S.K., Arvey R., Barciniak M., Benna M., Bleacher L., Brinckerhoff W.B., Eigenbrode J.L., Carignan D., Cascia M., Chalmers R.A., Dworkin J.P., Errigo T., Everson P., Franz H., Farley R., Feng S., Frazier G., Freissinet C., Glavin D.P., Harpold D.N., Hawk D., Holmes V., Johnson C.S., Jones A., Jordan P., Kellogg J., Lewis J., Lyness E., Malespin C.A., Martin D.K., Maurer J., McAdam A.C., McLennan D., Nolan T.J., Noriega M., Pavlov A.A., Prats B., Raaen E., Sheinman O., Sheppard D., Smith J., Stern J.C., Tan F., Trainer M., Ming D.W., Morris R.V., Jones J., Gundersen C., Steele A., Wray J., Botta O., Leshin L.A., Owen T., Battel S., Jakosky B.M., Manning H., Squyres S., McKay R.N.C.P., Raulin F., Sternberg R., Buch A., Sorensen P., Kline-Schoder R., Coscia D., Szopa C., Teinturier S., Baffes C., Feldman J., Flesch G., Forouhar S., Garcia R., Keymeulen D., Woodward S., Block B.P., Arnett K., Miller R., Edmonson C., Gorevan S., Mumm E.: The sample analysis at Mars investigation and instrument suite. Space Sci. Rev. 170(1/4), 401-478 (2012)

25. Sorensen, P., Kline-Schoder, R.J.: Vacuum systems for mini mass spectrometers. Presented at: the Pittsburgh Conference; Chicago, IL, March 2-6 (2014) 